\title{
Experiences of belittlement and harassment and their correlates among medical students in the United States: longitudinal survey
}

Erica Frank, Jennifer S Carrera, Terry Stratton, Janet Bickel, Lois Margaret Nora

\begin{abstract}
Objective To determine medical students' perceptions of having been harassed or belittled and their correlates, for the purposes of reducing such abuses.

Design Longitudinal survey.

Setting 16 nationally representative US medical schools. Participants 2884 students from class of 2003.

Main outcome measures Experiences of harassment and belittlement at freshman orientation, at entry to wards, and in senior year by other students, by residents or fellows, by preclinical professors, by clinical professors or attendings, or by patients.

Results 2316 students provided data (response rate 80.3\%). Among seniors, 42\% (581/1387) reported having experienced harassment and 84\% (1166/1393) belittlement during medical school. These types of abuse were caused by other students (11\% (158/1389) and 32\% (443/1390) of students experienced such harassment or belittlement, respectively). Harassment and belittlement was also caused by residents (27\% (374/1387) and $71 \%(993 / 1393))$, preclinical professors $(9 \%(131 / 1386)$ and $29 \%(398 / 1385))$, clinical professors $(21 \%(285 / 1386)$ and $63 \%$ $(878 / 1390))$, and patients (25\% (352/1387) and 43\%

$(592 / 1388))$. Only $13 \%(181 / 1385)$ of students classified any of these experiences as severe. Medical students who reported having been harassed or belittled did not differ significantly from those not reporting such experiences by sex, ethnicity, political orientation, or religion. They did differ significantly by chosen specialty and were significantly more likely to be stressed, depressed, and suicidal, to drink alcohol or to binge drink, and to state that their faculty did not care about medical students. They were also significantly less likely to be glad they trained to become a doctor.

Conclusion Most medical students in the United States report having been harassed or belittled during their training. Although few students characterised the harassment or belittlement as severe, poor mental health and low career satisfaction were significantly correlated with these experiences.
\end{abstract}

\section{Introduction}

Although copious literature examines the harassment and mistreatment of medical students, ${ }^{\text {w1-w21 }}$ few recent national studies in both sexes have investigated the extent of these broad and ever changing phenomena. We hypothesised that such experiences are relatively common and extend beyond sexual harassment, and that the consequences for affected students are both personal and professional.

\section{Methods}

All students in the class of 2003 at 16 US medical schools were eligible to participate in the study. Questionnaires were administered to students on three occasions during their medical training: at freshman orientation, at entry to wards (typically at transition between second and third years), and in their senior year.

Our sampling frame of schools was designed to be representative of US medical schools for age (freshman average 24 years $v 24$ nationally), school size (average students per school $563 v 527)$, National Institutes of Health research ranking (school average $64 v 62$ nationally), balance between private and public schools ( $51 \%$ private $v 41 \%$ ), under-represented minority groups (queried as black or African-American and nonHispanic, Hispanic or Latino, and Native Americans 13\% v 11\%), sex (45\% women $v 43 \%$ ), and geographical distribution. ${ }^{1-4}$ We excluded a 17th school in 2002 for non-adherence to protocol.

The questionnaires were administered outside of classrooms or training time and were confidential. Students were told that they could withdraw from the study at any time. When required we used Dillman's five stage mailing process ${ }^{5}$ to maximise response rates.

Students' responses were linked across time using a unique identifier consisting of mother's initials at birth and father's first two initials (first and middle names). Of the 2316 students who provided responses, $71.6 \%(\mathrm{n}=1658)$ did so at more than one time point. The overall response rate across all three periods was $80.3 \%$; a median $3 \%$ of students did not respond to individual questionnaire items.

In the second and third questionnaires, students responded to 10 separate questions asking whether they had been harassed or belittled during medical school (never, some, severely) by other students, residents or fellows (fellows being those who had already completed their residencies but were being trained in a subspecialty or were in research), preclinical professors, clinical professors or attendings (clinical supervisors), or patients. These questions were omitted from the first questionnaire because students would not have had the opportunity for exposure to harassment and belittlement in medical school at the time of freshman orientation. As a small number of participants reported severe harassment or belittlement $(<10 \%$ for all categories), we collapsed the categories for "some" and "severely" into one category.

We cross tabulated each of the 10 questions on harassment and belittlement with students' demographic characteristics,

References w1-w21 are on bmj.com 
questions on mental health (history of clinically diagnosed depression, suicide attempts or ideations, having felt downhearted or blue in the past four weeks, stress in the past year, and alcohol consumption), and perceived environment or attitudinal items on a five point Likert scale from strongly agree to strongly disagree ("Sometimes I feel like I have little influence over the things that happen to me," "I am mostly satisfied with life," "I have a good mentor," "Our faculty care about the medical students," and "I'm glad I chose to become a doctor"). We carried out $\chi^{2}$ tests and determined associated $\mathrm{P}$ values on each of the cross tabulations. As a result of the cumulative nature of the harassment and belittlement questions, we used only the data for senior years in the bivariate analyses. We also queried political orientation (on a five point scale from very liberal to very conservative) and religion.

We carried out two global tests of significance to assess the overall relation between current depressive state and perception of the medical school environment with experiences of harassment and belittlement. The models were run by utilising linear regression with repeated measures over entry to wards and senior year. Each test, one for all sources of harassment and another for all sources of belittlement, enabled us to examine whether the variables for depression and school environment were significantly related to any of the sources of harassment or belittlement after controlling for depressive state at entry to medical school, sex, ethnicity, marital status, and time point. We analysed data using generalised estimating equations ${ }^{6-8}$ with a logit link function to provide the global test. This explicitly tests for effect in all outcome measures in the harassment and belittlement groups. To account for the clustering of students within schools we used the Multilog procedure with SAS callable SUDAAN. Time was incorporated with a single indicator variable. An exchangeable correlation structure was assumed. We specifically investigated two time points to examine the changes in harassment and belittlement throughout medical school. Because of the construction of the set of variables for harassment and belittlement, we carried out a large number of significance tests. To reduce the risk of false positive results, $\mathrm{P}$ values greater than 0.01 should be interpreted with caution.

\section{Results}

At entry to wards, 8\% (129/1553) of medical students reported having been harassed by residents or fellows, $8 \%(124 / 1550)$ by clinical professors or attendings, and $10 \%(161 / 1556)$ by patients compared with $27 \%(374 / 1387), 21 \%$ (285/1386), and $25 \%(352 / 1387)$ of students in their senior year (figure). At entry to wards, $28 \%(434 / 1552)$ of students reported having been belittled by residents or fellows, $32 \%(498 / 1546)$ by clinical professors or attendings, and 22\% $(335 / 1556)$ by patients compared with $71 \%(993 / 1393), 63 \%(878 / 1390)$, and $43 \%(592 / 1388)$ of students in their senior year. Rates of harassment and belittlement by students and preclinical professors did not change significantly between these two time points. In their senior year, 11\% (158/1389) of students reported ever having been harassed by other students and $9 \%(131 / 1386)$ by preclinical professors; 32\% (443/1390) had been belittled by students and $29 \%(398 / 1385)$ by preclinical professors. Overall, $42 \%$ $(581 / 1387)$ of students who returned the survey in the senior year reported having ever been harassed by any of the five groups (other students, residents or fellows, preclinical professors, clinical professors or attendings, or patients), $84 \%$ $(1166 / 1393)$ indicated ever having been belittled, 85\% $(1182 / 1385)$ reported ever having been harassed or belittled,

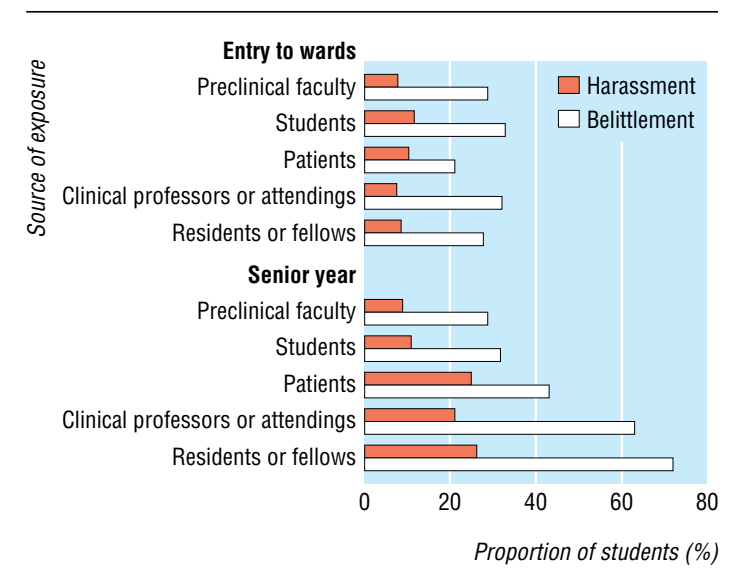

Proportion of medical students experiencing harassment or belittlement at entry to wards or in senior year

and 40\% (556/1385) had experienced both. Only $13 \%$ $(181 / 1385)$ of students classified any of these experiences as severe (data not shown).

Across groups, sex was marginally significant only for harassment by preclinical professors (11\% (83/736) men $v 7 \%$ $(47 / 648)$ women, $\mathrm{P}=0.04$; table 1$)$. Ethnicity differed significantly only for harassment by preclinical and clinical professors or attendings. No statistically significant relations were observed between political orientation or religion with harassment or belittlement (table 2). Regardless of religion, no strong effect was found between strength of religious identity and reported harassment or belittlement (data not shown).

Statistically significant relations between specialty and harassment or belittlement existed across most groups; however, no one specialty was especially associated with students being most often harassed or belittled. Students intending to specialise in family medicine were, however, among three specialties reporting the highest incidence of harassment by residents or fellows (32\%, 36/111), clinical professors or attendings $(30 \%$, $33 / 111)$, and patients $(29 \%, 32 / 112)$, and the highest incidence of belittlement by students $(38 \%, 42 / 112)$, residents or fellows $(75 \%, 85 / 113)$, and clinical professors or attendings $(69 \%$, $78 / 113)$.

Although no significant relations were observed between clinically diagnosed depression and harassment (table 1), higher rates of belittlement by students, resident or fellows, and clinical professors or attendings were reported by students stating a past clinical diagnosis of depression (table 2). Having been harassed by residents or fellows or by clinical professors or attendings, or having been belittled by other students, clinical professors or attendings, or patients were all significantly associated with ever having made a suicide attempt (data not shown, 25 seniors). Higher rates (13\% higher on average) of harassment and belittlement were observed across all groups reporting suicidal ideations in the past year. Students who reported feeling blue most or all of the time averaged greater than $40 \%$ more harassment and belittlement than did students who reported not having felt blue at all in the past four weeks. Removal of the few students $(13 / 1846)$ with a history of suicide attempts before medical school had no effect on the statistical significance or interpretation of the other mental health variables. Stress in the past 12 months was significantly related to nearly all sources of harassment and belittlement.

Alcohol consumption was significantly correlated with all sources of harassment and belittlement, except belittlement by 
Research

Table 1 Characteristics of US medical students experiencing harassment from other students, residents, faculty members, or patients. Values are numbers (percentages) experiencing harassment unless stated otherwise

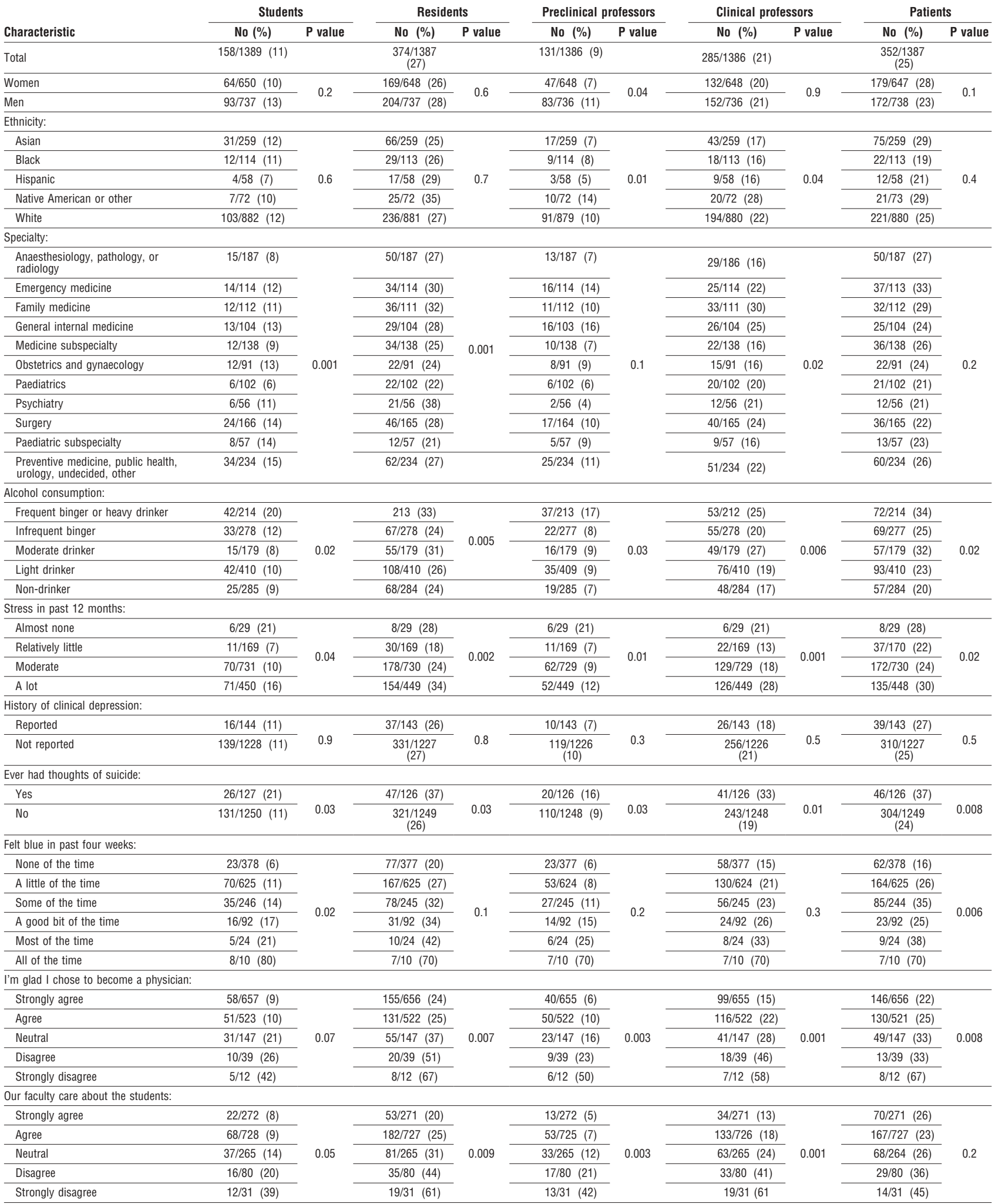

$\mathrm{P}$ values derived from $\chi^{2}$ test.

residents or fellows and by patients. Overall, those who reported frequent binge drinking reported the highest rates of harassment and belittlement. 
Table 2 Characteristics of US medical students experiencing belittlement from other students, residents, faculty members, or patients. Values are numbers (percentages) experiencing belittlement unless stated otherwise

\begin{tabular}{|c|c|c|c|c|c|c|c|c|c|c|}
\hline \multirow[b]{2}{*}{ Characteristic } & \multicolumn{2}{|c|}{ Students } & \multicolumn{2}{|c|}{ Residents } & \multicolumn{2}{|c|}{ Preclinical professors } & \multicolumn{2}{|c|}{ Clinical professors } & \multicolumn{2}{|c|}{ Patients } \\
\hline & No (\%) & $P$ value & No (\%) & $P$ value & No (\%) & $P$ value & No (\%) & $P$ value & No $(\%)$ & $P$ value \\
\hline Total & $443 / 1390$ & - & $\begin{array}{c}993 / 1393 \\
(71)\end{array}$ & - & $\begin{array}{c}398 / 1385 \\
(29)\end{array}$ & - & $878 / 1390$ & - & $\begin{array}{c}592 / 1388 \\
(43)\end{array}$ & - \\
\hline Women & $193 / 650(30)$ & \multirow{2}{*}{0.3} & $463 / 652(71)$ & \multirow{2}{*}{0.9} & $183 / 648(28)$ & \multirow{2}{*}{0.7} & $412 / 651 \quad(63)$ & \multirow{2}{*}{0.9} & $285 / 647(44)$ & \multirow{2}{*}{0.5} \\
\hline Men & $248 / 738$ (34) & & $528 / 739(71)$ & & $214 / 735(29)$ & & $464 / 737$ (63) & & $305 / 739(41)$ & \\
\hline \multicolumn{11}{|l|}{ Ethnicity: } \\
\hline Asian & $88 / 260$ (34) & \multirow{5}{*}{0.9} & 193/260 (74) & \multirow{5}{*}{0.1} & $70 / 259(27)$ & & 169/259 (65) & & $119 / 260(46)$ & \\
\hline Black & $35 / 114 \quad(31)$ & & $75 / 114(66)$ & & 28/112 (25) & & $62 / 114(54)$ & & 33/112 (29) & \\
\hline Hispanic & $15 / 57(26)$ & & $42 / 58 \quad(72)$ & & $16 / 58(28)$ & 0.9 & $37 / 58(64)$ & 0.7 & $18 / 57$ & 0.06 \\
\hline Native American or other & $22 / 71 \quad(31)$ & & $55 / 72(76)$ & & $21 / 72(29)$ & & $46 / 72(64)$ & & $32 / 71 \quad(45)$ & \\
\hline White & $281 / 884(32)$ & & $625 / 885(71)$ & & $262 / 880(30)$ & & $560 / 883(63)$ & & $387 / 884$ (44) & \\
\hline Specialty: & & & & & & & & & & \\
\hline $\begin{array}{l}\text { Anaesthesiology, pathology, } \\
\text { or radiology }\end{array}$ & $58 / 186$ & & $131 / 188(70)$ & & 49/187 (26) & & $113 / 187(60)$ & & $86 / 187(46)$ & \\
\hline Emergency medicine & 37/114 (33) & & $81 / 114$ & & 42/114 (37) & & $73 / 114$ (64) & & $54 / 114$ & \\
\hline Family medicine & 42/112 (38) & & $85 / 113(75)$ & & 35/112 (31) & & $78 / 113(69)$ & & 46/112 (41) & \\
\hline General internal medicine & $36 / 105 \quad(34)$ & & $76 / 105$ (72) & & $36 / 105$ (34) & & $68 / 105(65)$ & & $48 / 104(46)$ & \\
\hline Medicine subspecialty & 40/137 (29) & & 101/138 (73) & & $35 / 138$ (25) & & $88 / 138(64)$ & & $56 / 138(41)$ & \\
\hline Obstetrics and gynaecology & $28 / 91 \quad(31)$ & 0.9 & $65 / 91(71)$ & 0.001 & $18 / 91(20)$ & 0.1 & $53 / 91 \quad(58)$ & 0.5 & $36 / 91 \quad(40)$ & 0.1 \\
\hline Paediatrics & $30 / 103$ (29) & & $75 / 103$ (73) & & $34 / 103$ (33) & & $69 / 103(67)$ & & $41 / 103(40)$ & \\
\hline Psychiatry & $18 / 56 \quad(32)$ & & $43 / 56(77)$ & & $13 / 56(23)$ & & $37 / 56(66)$ & & $27 / 55(49)$ & \\
\hline Surgery & $54 / 167 \quad(32)$ & & $116 / 166(70)$ & & $53 / 164 \quad(32)$ & & $100 / 166(60)$ & & $54 / 166$ (33) & \\
\hline Paediatric subspecialty & $18 / 56(32)$ & & $36 / 56(64$ & & $13 / 55 \quad(24)$ & & $34 / 56(61)$ & & $26 / 56(46)$ & \\
\hline $\begin{array}{l}\text { Preventive medicine, public } \\
\text { health, urology, undecided, } \\
\text { other }\end{array}$ & 69/235 (29) & & 163/235 (69) & & $61 / 233 \quad(26)$ & & 145/233 (62) & & $98 / 234(42)$ & \\
\hline Alcohol consumption: & & & & & & & & & & \\
\hline $\begin{array}{l}\begin{array}{l}\text { Frequent binger or heavy } \\
\text { drinker }\end{array} \\
\end{array}$ & $85 / 214 \quad(40)$ & & $164 / 213(77)$ & & $90 / 213(42)$ & & $152 / 213(71)$ & & $106 / 213(50)$ & \\
\hline Infrequent binger & $88 / 278 \quad(32)$ & & 199/279 (71) & & 77/278 (28) & & $170 / 278(61)$ & & $108 / 278$ (39) & \\
\hline Moderate drinker & $62 / 180(34)$ & 0.007 & $130 / 180$ (72) & 0.09 & $53 / 179(30)$ & 0.002 & 117/179 (65) & 0.001 & $88 / 178$ (49) & 0.1 \\
\hline Light drinker & $110 / 409(27)$ & & $295 / 411(72)$ & & $103 / 410(25)$ & & $264 / 411$ (64) & & $172 / 410(42)$ & \\
\hline Non-drinker & $92 / 286 \quad(32)$ & & $192 / 287(67)$ & & $69 / 282(24)$ & & $161 / 286(56)$ & & $110 / 286(38)$ & \\
\hline Stress in past 12 months: & & & & & & & & & & \\
\hline Almost none & $11 / 29(38)$ & & $12 / 29(41)$ & & $6 / 28(21)$ & & $11 / 29(38)$ & & $11 / 28(39)$ & \\
\hline Relatively little & $34 / 169(20)$ & 0.003 & & 0.03 & $35 / 169(21)$ & 0.002 & $92 / 168 \quad(55)$ & 0.004 & $60 / 169(36)$ & 0.06 \\
\hline Moderate & $211 / 730(29)$ & 0.000 & $518 / 733(71)$ & 0.00 & $210 / 728(29)$ & 0.002 & $450 / 733(61)$ & .004 & $319 / 732$ (44) & 0.00 \\
\hline A lot & $184 / 452(41)$ & & $353 / 452(78)$ & & $145 / 450$ (32) & & $319 / 450(71)$ & & / (449 (44) & \\
\hline History of clinical depression: & & & & & & & & & & \\
\hline Reported & $64 / 144 \quad(44)$ & & $117 / 145(81)$ & & 47/144 (33) & & 106/143 (74) & & $69 / 143(48)$ & \\
\hline Not reported & $375 / 1230(31)$ & 0.004 & $\begin{array}{c}866 / 1232 \\
(70)\end{array}$ & 0.01 & $\begin{array}{c}345 / 1225 \\
(28)\end{array}$ & 0.2 & $761 / 1231(62)$ & 0.007 & $\begin{array}{c}518 / 1229 \\
(42)\end{array}$ & 0.08 \\
\hline Ever had thoughts of suicide: & & & & & & & & & & \\
\hline Yes & $63 / 126(50)$ & & 104/126 (83) & & $53 / 126 \quad(42)$ & & $98 / 126(78)$ & & $68 / 126(54)$ & \\
\hline No & $376 / 1252(30)$ & 0.002 & $\begin{array}{c}883 / 1255 \\
(70)\end{array}$ & 0.02 & $\begin{array}{c}345 / 1248 \\
(28)\end{array}$ & 0.01 & $773 / 1252(62)$ & 0.002 & $\begin{array}{c}521 / 1250 \\
(42)\end{array}$ & 0.008 \\
\hline Felt blue in past four weeks: & & & & & & & & & & \\
\hline None of the time & $78 / 379$ (21) & & $235 / 379$ (62) & & $75 / 374(20)$ & & $207 / 378$ (55) & & $123 / 377$ (33) & \\
\hline A little of the time & $207 / 625$ (33) & & $461 / 627(74)$ & & $179 / 626(29)$ & & $398 / 626$ (64) & & $280 / 627(45)$ & \\
\hline Some of the time & $101 / 247$ (41) & م001 & $189 / 247(77)$ & 000007 & $91 / 246(37)$ & 0008 & $178 / 246(72)$ & 001 & $125 / 245$ (51) & 0.1 \\
\hline A good bit of the time & $35 / 92$ (38) & 0.001 & $76 / 92$ (83) & 0.0007 & $32 / 92$ (35) & 0.008 & $63 / 92(68)$ & 0.001 & $41 / 91$ (45) & 0.01 \\
\hline Most of the time & $13 / 23(57)$ & & $17 / 24(71)$ & & $12 / 23(52)$ & & $16 / 24(67)$ & & $11 / 24(46)$ & \\
\hline All of the time & $7 / 10(70)$ & & $6 / 10(60)$ & & $6 / 10(60)$ & & $6 / 10(60)$ & & $6 / 10(60)$ & \\
\hline $\begin{array}{l}\text { I'm glad I chose to become a } \\
\text { physician: }\end{array}$ & & & & & & & & & & \\
\hline Strongly agree & $185 / 655(28)$ & & $445 / 657$ (68) & & $164 / 654(25)$ & & $384 / 656$ (59) & & $250 / 655(38)$ & \\
\hline Agree & $171 / 526(33)$ & & $388 / 527$ (74) & & $147 / 523(28)$ & & $349 / 526(66)$ & & $237 / 524$ (45) & \\
\hline Neutral & $60 / 147(41)$ & 0.006 & 109/147 (74) & 0.02 & $51 / 146 \quad(35)$ & 0.02 & $97 / 146(66)$ & 0.01 & $74 / 147(50)$ & 0.008 \\
\hline Disagree & $17 / 39$ (44) & & $33 / 39$ (85) & & $21 / 39(54)$ & & $30 / 39$ (77) & & $16 / 39(41)$ & \\
\hline Strongly disagree & $6 / 12(50)$ & & 9/12 (75) & & $8 / 12(67)$ & & 9/12 (75) & & $9 / 12(75)$ & \\
\hline $\begin{array}{l}\text { Our faculty care about the } \\
\text { students: }\end{array}$ & & & & & & & & & & \\
\hline Strongly agree & $62 / 273$ (23) & & 167/273 (61) & & $53 / 272$ (19) & & 134/273 (49) & & 105/272 (39) & \\
\hline Agree & $223 / 729$ (31) & & $523 / 730$ (72) & & $182 / 724$ (25) & & 465/728 (64) & & $312 / 727$ (43) & \\
\hline Neutral & 97/266 (37) & 0.003 & 199/266 (75) & 0.01 & $96 / 265$ (36) & $<0.001$ & 180/266 (68) & 0.002 & $115 / 265$ (43) & 0.2 \\
\hline Disagree & $40 / 78(51)$ & & $69 / 80(86)$ & & $43 / 80(54)$ & & $64 / 79(81)$ & & $38 / 80(48)$ & \\
\hline Strongly disagree & $16 / 31$ & & 25/31 (81) & & 18/31 (58) & & $26 / 31$ & & $16 / 31$ & \\
\hline
\end{tabular}

$P$ values derived from $\chi^{2}$ test. 
Table 3 Global test of predictors of harassment and belittlement of US medical students with repeated measures at entry to wards and senior year, controlling for mental health at freshman year

\begin{tabular}{|c|c|c|c|}
\hline Variable & $\begin{array}{r}\text { Odds } \mathrm{r} \\
\mathrm{h}\end{array}$ & $\begin{array}{l}\text { atio }(95 \% \mathrm{Cl}) \text { for } \\
\text { tarassment }\end{array}$ & $\begin{array}{l}\text { Odds ratio }(95 \% \mathrm{Cl}) \text { for } \\
\text { belittlement }\end{array}$ \\
\hline Women & 0.86 & $(0.68$ to 1.1$)$ & 0.97 (0.81 to 1.17$)$ \\
\hline Men & & 1.00 & 1.00 \\
\hline Ethnicity: & & - & - \\
\hline White & 0.96 & (0.79 to 1.17$)$ & 1.09 (0.92 to 1.28$)$ \\
\hline Asian & 0.95 & (0.71 to 1.28$)$ & 1.19 (0.91 to 1.56$)$ \\
\hline Other & & 1.00 & 1.00 \\
\hline Ever been married: & & - & - \\
\hline Yes & 0.98 & (0.79 to 1.22$)$ & 1.02 (0.86 to 1.21$)$ \\
\hline No & & 1.00 & 1.00 \\
\hline Felt blue in past four weeks: & & $* * *$ & $\star * \star *$ \\
\hline None of the time & & 1.00 & 1.00 \\
\hline A little, some, a good bit of the time & 1.44 & (1.10 to 1.87$)$ & 1.55 (1.33 to 1.80$)$ \\
\hline Most or all of the time & 3.36 & (1.50 to 7.52$)$ & 1.90 (0.97 to 3.69$)$ \\
\hline $\begin{array}{l}\text { Felt blue in past four weeks at } \\
\text { freshman year: }\end{array}$ & & - & ** \\
\hline None of the time & & 1.00 & 1.00 \\
\hline A little, some, a good bit of the time & 1.10 & (0.85 to 1.42$)$ & 1.26 (1.09 to 1.45$)$ \\
\hline Most or all of the time & 0.93 & (0.35 to 2.44$)$ & 1.33 (0.73 to 2.44$)$ \\
\hline $\begin{array}{l}\text { I'm glad I chose to become a } \\
\text { physician: }\end{array}$ & & $* \star *$ & * \\
\hline Strongly agree or agree & 0.45 & (0.29 to 0.69$)$ & 0.79 (0.49 to 1.27$)$ \\
\hline Neutral & 0.70 & (0.41 to 1.20$)$ & 1.09 (0.67 to 1.78$)$ \\
\hline Strongly disagree or disagree & & 1.00 & 1.00 \\
\hline $\begin{array}{l}\text { Our faculty care about the medical } \\
\text { students: }\end{array}$ & & 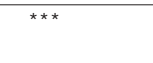 & $\star \star \star *$ \\
\hline Strongly agree or agree & 0.43 & (0.31 to 0.60$)$ & 0.43 (0.33 to 0.55$)$ \\
\hline Neutral & 0.55 & (0.38 to 0.81$)$ & 0.61 (0.49 to 0.76$)$ \\
\hline Strongly disagree or disagree & & 1.00 & 1.00 \\
\hline Time point: & & $* \star *$ & $\star * \star *$ \\
\hline Entry to wards & & 1.00 & 1.00 \\
\hline Senior year & 2.49 & (1.77 to 3.50$)$ & 2.41 (1.77 to 3.28$)$ \\
\hline
\end{tabular}

decisions was inversely associated with harassment and belittlement across nearly all groups. Likewise, having a lower feeling of control and being less satisfied with life were associated with higher rates of harassment and belittlement, whereas having a good mentor was inversely associated with being harassed by residents and clinical professors or attendings and being belittled by students, preclinical professors, and clinical professors or attendings (data not shown).

After controlling for sex, ethnicity, marital status, having felt blue in the past four weeks at orientation, and time, both harassment and belittlement (table 3) were significantly related to having felt blue in the past four weeks, career satisfaction, and belief that the faculty care about the medical students.

\section{Discussion}

Levels of belittlement and harassment are high among medical students in the United States: $40 \%$ of students in their senior year reported having been harassed and $84 \%$ had been belittled. Students graduating a decade ago also reported high prevalences, with $46 \%$ experiencing some form of harassment and $41 \%$ some form of discrimination from instructors or supervisors while at medical school. ${ }^{\mathrm{w} 1}$ In our study some of these experiences were caused by other students and preclinical professors, but most commonly they were caused by residents, clinical professors, and (to a lesser extent for belittlement) patients. In 1991, a study reported that residents and attendings (those providing the most direct role models for students) were most likely to be a frequent source of harassment; others, such as nurses or other staff (not included in our study) may also harass. ${ }^{9}$

Harassment and belittlement have long been considered common and consequential in medical schools: $81 \%$ of seniors surveyed at one school in the 1980s reported being abused; $69 \%$ of those abused reported that at least one such episode was of "major importance and very upsetting."ws Although only 13\% of students in this study classified any of these experiences as severe, many serious correlates were professional and personal. Perhaps most significantly, those who reported having been harassed or belittled from any source were consistently and substantively less likely to be glad they chose to become a doctor. Similarly, they reported a lower locus of control (an extremely powerful predictor of doctors' career satisfaction ${ }^{10}$ ), less overall satisfaction with life, and felt unmentored and that their faculty did not care about them; others have also showed correlations between abuse and lower levels of confidence in students' clinical skills ${ }^{\mathrm{w4}}$ and in satisfaction with their profession. ${ }^{\mathrm{w5-w7}}$

Another finding was variations between specialties. Literature has shown an increased prevalence of harassing or discriminatory behaviours related to surgery, ${ }^{\text {w8-w10 }}$ obstetrics and gynaecology, ${ }^{11 \mathrm{w} 8 \mathrm{w} 11-\mathrm{w} 13}$ and, somewhat less often, paediatrics. ${ }^{\mathrm{w} 8 \mathrm{w12} \text { w13 }}$ We noted that students embarking on careers in family medicine reported higher levels of harassment and belittlement. Historically the reported prevalence of abusive behaviour in family medicine has tended to be lower than in other disciplines, ${ }^{\mathrm{w} 8}{ }^{\mathrm{w} 12}$ and at least one study has found it the least culpable for harassment and belittlement. ${ }^{\text {w14 }}$ Since humanism, ${ }^{12}$ counselling skills, ${ }^{13}$ and high levels of psychosocial involvement ${ }^{14}$ may be particularly important to family medicine, these students may be more attuned to issues of mistreatment or perceive a broader range of behaviours as harassing or belittling. Alternatively they may have chosen family medicine as a reaction to harassment or belittlement encountered on other clerkships, or current experiences in family medicine may be different from those in the past.

Several personal characteristics were associated with reporting having been harassed or belittled. A smaller proportion of students from ethnic minorities reported harassment from their professors than did white students (with the exception of those $(\mathrm{n}=72)$ who were classified as Native American or "other"). It is encouraging that this is their perceived experience, given efforts to increase the prevalence of under-represented minorities in medical schools in the United States. ${ }^{2}$ Similarly, in the women physicians' health study $(\mathrm{n}=4501)$, whereas ethnically based harassment was higher in under-represented minorities, ${ }^{15}$ Asian women doctors (an over-represented population among women doctors) were least likely to report sexual or gender based harassment, and such rates in black and Hispanic students were comparable to those in white students. ${ }^{16}$ Similarly, in the current study neither those with strong political beliefs nor religious minorities consistently experienced higher levels of harassment or belittlement. This finding differs from that of the women physicians' health study, where those who were politically conservative were less likely to report gender based harassment. ${ }^{17}$ This may be attributable to differing questionnaire items (that is, specifically querying sex based harassment), populations (that is, women doctors of all ages in 1993-4 compared with medical students of both sexes in 2002-3), experiences (conservative women might challenge sex stereotypes less), or perceptions (conservative women may be less likely to consider traditional attitudes offensive). 


\section{What is already known on this topic}

Most of the large scale studies on harassment and belittlement of US medical students have been cross sectional and of limited generalisability

\section{What this study adds}

Most medical students in the United States report having been harassed or belittled during their training

Poor mental health and low career satisfaction are significantly associated with being harassed or belittled

Given that previous research has often documented a higher prevalence of harassing and discriminatory behaviours towards women medical students, ${ }^{\text {w8 }}$ w14 w16-w18 the absence of a significant sex effect in the present study may be noteworthy. However, studies that have examined more general mistreatment or abuse among medical students have found far less disparity between sexes, ${ }^{\mathrm{w} 2}{ }^{\mathrm{w} 5}$ and that sex based differences mainly occur for sexual harassment, ${ }^{\mathrm{w} 19}$ prompting researchers to examine sexual harassment and other forms of discrimination as separate constructs. ${ }^{\mathrm{w} 20}$ We believe that the lack of consistent, significant differences between men and women in our sample is probably a result of students responding to incidents involving a much broader range of dysfunctional practices than just sexual or gender-based harassment.

Although students with psychopathology may perform or perceive differently from other students, our data and that of others suggest that abusive behaviour, especially by those in positions of power, contributes to students' poor mental health. The women physicians' health study showed significantly more frequent histories of depression and suicide attempts among doctors who had experienced gender based or sexual harassment, ${ }^{16}$ with over four times the rate of suicide attempts $(3.0 \%$ v $0.7 \%, \mathrm{P}<0.001)$ among those who had experienced moderate or severe harassment compared with those who had experienced mild or no harassment. ${ }^{18}$ A longitudinal cohort study of 137 medical students (72\% reporting abuse during medical training) found that abuse was significantly related to most psychopathological outcomes, after controlling for pre-existing psychopathology. ${ }^{\text {w21 }}$ Students on internal medicine clerkships at 11 medical schools $(n=1072)$ associated a lack of confidence and feelings of depression, anger, and humiliation with abusive experiences. ${ }^{\mathrm{w} 5}$

Perceptions of harassment and belittlement do depend on the individual, and our study, although cohort based, cannot clearly identify directionality or causation. Although few students believed that the incidents they had experienced were severe, most had experienced these degradations, and their effects were personally and professionally widespread and significant. Our data show that students who believe they have been harassed or belittled are significantly less satisfied with their career choices, lives, and relationships with their teachers, and show diverse and serious psychological correlates. If the medical profession is serious about creating a satisfied workforce and about teaching students to behave ethically with colleagues and patients, we ourselves must behave in an ethically appropriate and sensitive way. This problem seems to be widespread in both the United
States and some other countries, ${ }^{19 \mathrm{w} 6 \mathrm{w} 19}$ to not have significantly diminished in the United States despite considerable attention, ${ }^{w 7}$ and to warrant further attention.

Contributors: EF (principle investigator) conceived the study, conceived of and had primary responsibility for structuring the analyses, and wrote the first and final drafts of most of the sections besides the methods. JSC conceived of and had primary responsibility for carrying out the analyses, wrote the first drafts of most of the methods section, and helped edit the manuscript. EF and JSC are guarantors. TS helped structure the analyses, wrote the first drafts of substantive components of the discussion section, and helped edit the manuscript. JB helped structure the analyses, contributed components of the discussion section, and helped edit the manuscript. LMN helped structure the analyses, contributed components of the discussion section, and helped edit the manuscript.

Funding: None.

Competing interests: None declared.

Ethical approval: This study was approved by the Emory University institutional review board.

1 American Association of Medical Colleges. Matriculant age at anticipated matriculation, 1992-2001. AAMC data warehouse: applicant matriculant file. www.aamc.org/data/facts/archive/famg112001a.htm (accessed 20 Jan 2006).

2 American Association of Medical Colleges. FACTS-applicants, matriculants, and graduates-new entrants by gender and race/ethnicity. www.aamc.org/data/facts/ archive/famg52001a.htm (accessed 20 Jan 2006).

3 American Association of Medical Colleges. AAMC data warehouse: student records system as of December 12, 2000, reflecting those actively enrolled on October 31, 2000. www.aamc.org/data/facts/archive/famg82001.htm (accessed 20 Jan 2006).

4 National Institutes of Health. Support to US medical schools, fiscal year 2000. http:// grants.nih.gov/grants/award/rank/medschrank00.txt (accessed 20 Jan 2006).

5 Dillman DA. Mail and internet surveys. the tailored design method. 2nd ed. New York, NY: Wiley, 2000.

6 National Institute of Neurological Disorders and Stroke rt-PA Stroke Study Group. Tissue plasminogen activator for acute ischemic stroke. N Engl J Med 1995;333:1581-7.

7 Lefkopoulou M, Moore D, Ryan L. The analysis of multiple correlated binary outcomes: application to rodent teratology experiments. J Am Stat Assoc 1989;84:810-5.

Zeger SL, Liang KY. Longitudinal data analysis for discrete and continuous outcomes. Biometrics 1986;42:121-30.

9 Baldwin DC, Hughes PH, Conard SE, Storr CL, Sheehan DV. Substance use among senior medical students: a survey of 23 medical schools. JAMA 1991;265:2074-8.

10 Frank E, McMurray JE, Linzer M, Elon L. Career satisfaction of US women physicians. Frank E, McMurray JE, Linzer M, Elon
Arch Intern Med 1999;159:1417-26.

11 Lyon DS. Where have all the young men gone? Keeping men in obstetrics and gynecology. Obstret Gynecol 1997;90 (part 1):634-6.

12 Taylor AD. How to choose a medical specialty. 3rd ed. Philadelphia: WB Saunders, 1999.

13 Bergus GR, Levy BT, Randall CS, Dawson JD, Jogerst GJ. Skills that Iowa family physicians desire in a new physician partner. Fam Med 1997;29:618-24.

14 Marvel MK, Doherty WJ, Weiner E. Medical interviewing by exemplary family physicians. J Fam Pract 1998;47:343-8.

15 Corbie-Smith G, Frank E, Nickens HW, Elon L. Prevalences and correlates of ethnic harassment in the US women physicians' health study. Acad Med 1999;74:695-701.

16 Frank E, Brogan DJ, Mokdad AH, Simoes EJ, Kahn HS, Greenberg RS. Health-related behaviors of women physicians vs other women in the United States. Arch Intern Med behaviors of wor

17 Frank E, Brogan DJ, Schiffman M. Prevalence and correlates of harassment among US women physicians. Arch Intern Med 1998;158:352-8.

18 Frank E, Dingle AD. Self-reported depression and suicide attempts among US women physicians. Am J Psychiatry December 1999;156:1887-94.

19 Uhari M, Kokkonen J, Nuutinen M, Vainionpaa L, Rantala H, Lautala P, et al. Medical student abuse: an international phenomenon. JAMA 1994;271:1049-51. (Accepted 3 July 2006)

doi 10.1136/bmj.38924.722037.7C

Emory University School of Medicine, Department of Family and Preventive

Medicine, Atlanta, GA 30303, USA

Erica Frank professor

Jennifer S Carrera consultant

Office of Medicine Academic Affairs, University of Kentucky College of Medicine, KY, USA

Terry Stratton assistant dean

Faculty Career and Diversity, Falls Church, VA, USA

Janet Bickel consultant

Northeastern Ohio Universities College of Medicine, Rootstown, OH, USA

Lois Margaret Nora dean

Correspondence to: E Frank, Department of Health Care and Epidemiology,

University of British Columbia, Vancouver, BC, V6T 2K9 erica.frank@ubc.ca 